\title{
Efektivitas Ekstrak Daun Pegagan (Centella asiatica (L.) Urban ) terhadap Pertumbuhan Jamur Aspergillus flavus
}

\author{
Mohammad Wildan Habibi ${ }^{1 *}$, Mohammad Arfi Setiawan ${ }^{2)}$, Risa Munika Ulfa ${ }^{1)}$, Lin \\ Istiqomah $^{1)}$ \\ ${ }^{1)}$ Prodi Tadris IPA, Fakultas Tarbiyah dan Ilmu Keguruan, IAIN Jember \\ ${ }^{2)}$ Prodi Teknik Kimia, Fakultas Teknik, Universitas PGRI Madiun \\ *email: ziowildan@gmail.com
}

Received: 24/09/2018; Revised: 17/11/2018; Accepted: 17/11/2018

\begin{abstract}
Abstrak
Aspergillus flavus merupakan jamur yang bersifat aerobik karena memiliki kemampuan untuk tetap hidup jika kondisi medianya dipenuhi oksigen. Jamur mikroskopis ini dapat menghasilkan satu zat tertentu bernama aflatoxin. Ini adalah mikotoksin yang memiliki tingkat dampak toksik yang tinggi. Tujuan dari penelitian ini adalah untuk mengetahui pengaruh ekstrak daun dari Centella asiatica (L.) Urban terhadap pertumbuhan Aspergillus flavus. Metode yang digunakan dalam penelitian ini adalah Rancangan Acak Lengkap (RAL). Hasil penelitian diperoleh bahwa ekstrak daun pegagan (Centella asiatica (L.) Urban) berpengaruh terhadap pertumbuhan jamur Aspergillus flavus dengan Konsentrasi Hambat Minimum (KHM) pada konsentrasi 0,8\%.
\end{abstract}

Kata kunci: Aflatoksin, Aspergillus flavus, Centella asiatica, Mikotoksin

\begin{abstract}
Aspergillus flavus is one of aerobic fungi that be able to live in saturated oxygen. This microscopic fungi can produced one particular substance named aflatoxin. It is a mycotoxin that owns a high level of toxic impact. The objective of this research is to find out the impact of the leave extract of Centella asiatica (L.) Urban on the growth of Aspergillus flavus. The method applied in this research is complete random design (RAL). The results of the study showed that Centella asiatica (L.) Urban leaf extract had an effect on the growth of Aspergillus flavus fungi with a Minimum Inhibitory Concentration (MIC) at a concentration of $0.8 \%$.
\end{abstract}

Keyword: Aflatoxin, Aspergillus flavus, Centella asiatica, Mycotoxin

\section{PENDAHULUAN}

Aspergilus flavus merupakan jenis jamur yang bersifat aerobik karena dapat hidup dengan baik bila kondisi medium kaya akan oksigen dan termasuk jamur parasit yang dapat dijumpai pada kacang, sorgum, jagung, gandum (Hua, 2013). Jamur A. Flavus dapat menghasilkan zat antara lain: okhratoksin, trichotesen, sitrinin, zearalenon dan aflatoksin.
Aflatoksin berasal dari singkatan Aspergillus flavus toxin. Toksin ini pertama kali diketahui berasal dari cendawan A. Flavus yang berhasil diisolasi. Toksin ini dapat bersifat karsinogenik, mutagenik, dan tergolong metabolit jamur yang sangat mematikan. (Okoth et al., 2012).

Aflatoksin ini diklasifikasikan sebagai racun tingkat 1 oleh Badan 
Efektivitas Ekstrak Daun Pegagan (Centella asiatica (L.) Urban ) terhadap Pertumbuhan Jamur Aspergillus flavus

Internasional Penelitian Kanker (IARC). Dalam kehidupan sehari-hari banyak ditemukan pencemaran oleh jamur $A$. Flavus seperti daging, susu, keju, dan telur. Oleh karena itu perlu waspada dalam memilih bahan makanan sebelum dikonsumsi (Herzallah, 2013).

Dicanangkannya program Back to Nature dalam mengobati suatu penyakit merupakan pilihan yang tepat dalam mengobati penyakit. Tanaman pegagan (Centella asiatica (L.) Urban) merupakan salah satu tanaman obat yang memiliki banyak manfaat, sehingga menarik perhatian para ahli untuk meneliti dan mengembangkannya dalam rangka eksplorasi obat baru yang berasal dari alam. Pegagan merupakan tanaman tropis yang digunakan dalam dunia medis dibeberapa negara seperti Turki, Indonesia sejak berabad-abad lalu. Pegagan merupakan tanaman aromatik, berbentuk stolon dengan ukuran $15 \mathrm{~cm}$ (6 inci) yang dapat berkembang ditempat teduh, rawa, sawah, tepi sungai. Daunnya terdiri dari 13 simpul tiap batangnya dengan panjang 2$6 \mathrm{~cm}$, lebar 1,5 $-5 \mathrm{~cm}$ (Singh et al., 2010).

Studi ilmiah telah membuktikan berbagai senyawa kimia telah ditemukan pada tanaman Centella asiatica. Senyawa kimia ini sangat berperan penting dalam pengobatan karena mengandung komponen triterpen, saponin. Triterpen dari Centella asiatica terdiri dari banyak senyawa termasuk asiatic acid, madecassic acid, asiaticosside, madecassoside, brahmoside, brahmic acid, brahminosida, thankiniside, isothankunisode, centelloside, madasiatic acid, centic acid, dan cenellic acid. Komponen triterpen bisa terpengaruh oleh lokasi dan beragam kondisi lingkungan (James \& Dubery, 2009). Triterpen merupakan kelompok senyawa bioaktif heterogen dengan struktur terduri dari agiteron triterpen (sapogenin) dan satu atau lebih gula yang berikatan dengan glikosidik asetal (ester) (Costa et al., 2017).

\section{METODE PENELITIAN}

Penelitian ini dilaksanakan di Laboratorium Mikrobiologi Fakultas Matematika dan Ilmu Pengetahuan Alam Universitas Jember. Penelitian ini menggunakan Rancangan Acak Lengkap (RAL) dengan menggunakan 3 kali pengulangan. Semua alat dan bahan yang akan digunakan dalam penelitian ini harus dalam keadaan streril artinya pada bahan dan peralatan tersebut tidak didapatkan mikroba yang tidak diharapkan kehadirannya.

\section{Ekstraksi Daun Pegagan}

Daun tunggal berbentuk ginjal, bertangkai panjang sekitar $5-15 \mathrm{~cm}$, tepi bergerigi atau beringgit, kadang agak berambut, penampang 1-7 cm, letaknya tersusun dalam roset akar, berkumpul 2-10 helai daun.

Ekstraksi daun pegagan dimulai dengan daun pegagan dengan mengeringkan daun sampai bentuknya mudah diremas-remas. Daun pegagan yang sudah kering dihaluskan, beratnya sebesar 230 gram. Selanjutnya dimaserasi menggunakan pelarut etanol $96 \%$ dengan volume $1725 \mathrm{ml}$ (volume tesebut dihitung 7,5 kali lipat dari berat setelah diblender) dan disimpan dalam toples selama $3 \times 24$ jam sambil dilakukan pengadukan pada pagi dan sore hari maka akan diperoleh simplisia. Simplisia yang telah dimaserasi disaring dan diperoleh filtrat. Filtrat dipekatkan dengan menggunakan rotary evaporator dengan suhu $40{ }^{\circ} \mathrm{C}$ sampai 
Efektivitas Ekstrak Daun Pegagan (Centella asiatica (L.) Urban ) terhadap Pertumbuhan Jamur Aspergillus flavus

diperolah ekstrak kental sebesar 40 gram. Ekstrak kental yang dihasilkan selanjutnya disimpan di tempat sejuk sehingga dapat bertahan kurang lebih sampai 6 bulan.

\section{Uji Daya Hambat Ekstrak Daun Pegagan terhadap A. Flavus}

Pada uji pertama yang dilakukan adalah Uji Pendahuluan. Tujuan dari Uji Pendahuluan ini adalah untuk mencari rentangan konsentrasi ekstrak yang dapat menghambat pertumbuhan jamur $A$. Flavus. Konsentrasi yang digunakan $5 \%$, $10 \%, 15 \%, 20 \%, 25 \%, 30 \%, 35 \%, 40 \%$, $45 \%, 50 \%$, intrakonazol $10 \%$ sebagai kontrol positif, dan aquadest steril yang ditambah dengan tween sebagai kontrol negatif. Kemudian dilakukan pengujian lebih lanjut untuk mengetahui Konsentrasi Hambatan Minimum.

Sebelum dilakukan pengujian, dilakukan pembuatan medium dan suspensi spora A. Flavus terlebih dahulu. Selanjutnya, suspensi jamur diambil menggunakan mikropipet sebanyak $100 \mu 1$ dan dituang kedalam medium PDA di tabung reaksi besar yang sudah dicairkan sebelumnya, agar jamur dan medium bercampur secara homogen, maka dilakukan pencampuran dengan menggunakan vortex. Kemudian medium yang sudah bercampur dengan jamur dituang kedalam cawan petri steril dan dibiarkan hingga medium menjadi padat. Setelah medium padat, membuat lubang atau sumuran yang dibuat pada permukaan media dengan menggunakan pencetak agar berdiameter $0,5 \mathrm{~cm}$ yang sudah disterilkan. Selanjutnya diisi tiap lubang sumuran dengan ekstrak daun pegagan dengan volume ekstrak sebanyak $30 \mu$ l. Kemudian inkubasi pada suhu $30^{\circ} \mathrm{C}$ selama 96 jam atau 4 hari. Setelah inkubasi selama 96 jam, daya hambat ekstrak daun pegagan terhadap pertumbuhan A. Flavus dapat dilihat dengan mengukur zona bening yang terbentuk di sekitar sumuran dengan menggunakan jangka sorong. Selanjutnya perhitungan jumlah spora dilakukan mengguakan alat haemositometer. Penghitungan jumlah spora dilakukan 2 kali. Yang pertama dilakukan sebelum atau tanpa perlakuan yaitu tanpa ekstrak, sedangkan yang kedua dilakukan pada saat jamur telah diberi perlakuan dengan pemberian ekstrak daun pegagan sesuai dengan kadar hambat minimum (KHM).

\section{HASIL DAN PEMBAHASAN}

Hasil pengukuran luas zona hambat ekstrak daun pegagan (Centella asiatica (L.) Urban) terhadap pertumbuhan jamur A. Flavus dilakukan sebanyak tiga kali pengulangan. Adapun hasilnya dapat dilihat pada Tabel 1 .

Tabel 1. Hasil Uji Pendahuluan Daya Hambat $\left(\mathrm{cm}^{2}\right)$ Ekstak Daun Pegagan pada Konsentrasi 5\%, 10\%, 15\%, $20 \%, 25 \%, 30 \%, 35 \%, 40 \%, 45 \%$, dan $50 \%$.

\begin{tabular}{ccccc}
\hline Konsentrasi & \multicolumn{3}{c}{$\begin{array}{c}\text { Luas Zona } \\
\text { Hambat }\left(\mathbf{c m}^{2}\right)\end{array}$} & $\begin{array}{c}\text { Rata- } \\
\text { rata }\end{array}$ \\
\cline { 2 - 5 } & 1 & 2 & 3 & \\
\hline $5 \%$ & 0,39 & 0,39 & 0,40 & 0,39 \\
$10 \%$ & 0,53 & 0,53 & 0,55 & 0,54 \\
$15 \%$ & 0,62 & 0,63 & 0,61 & 0,62 \\
$20 \%$ & 0,72 & 0,70 & 0,69 & 0,70 \\
$25 \%$ & 0,8 & 0,83 & 0,82 & 0,82 \\
$30 \%$ & 0,90 & 0,92 & 0,92 & 0,91 \\
$35 \%$ & 1,00 & 0,99 & 0,99 & 0,99 \\
$40 \%$ & 1,02 & 1,03 & 1,03 & 1,03 \\
$45 \%$ & 1,05 & 1,05 & 1,05 & 1,05 \\
$50 \%$ & 1,06 & 1,06 & 1,06 & 1,06 \\
$\mathrm{~K}^{+}$ & 1,09 & 1,10 & 1,09 & 1,09 \\
$\mathrm{~K}^{-}$ & 0 & 0 & 0 & 0 \\
\hline
\end{tabular}

Zona hambat ekstrak daun pegagan (Centella asiatica (L.) Urban) terhadap pertumbuhan jamur A. Flavus pada 
Efektivitas Ekstrak Daun Pegagan (Centella asiatica (L.) Urban ) terhadap Pertumbuhan Jamur Aspergillus flavus

konsentrasi 5\% - 50\% dapat dilihat pada Gambar 1 dan Gambar 2.

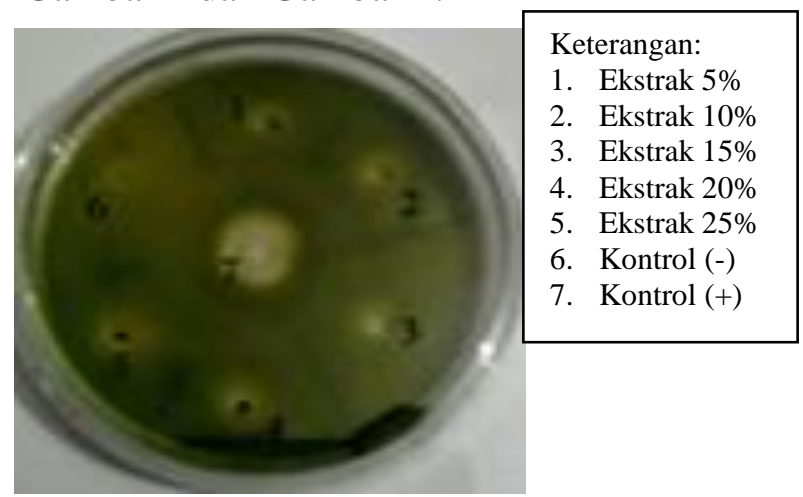

Gambar 1. Zona Hambat Ekstrak Daun Pegagan (Centella asiatica (L.) Urban) terhadap Jamur A. Flavus pada Konsentrasi 5\%, 10\%, 15\%, $20 \%$, dan $25 \%$

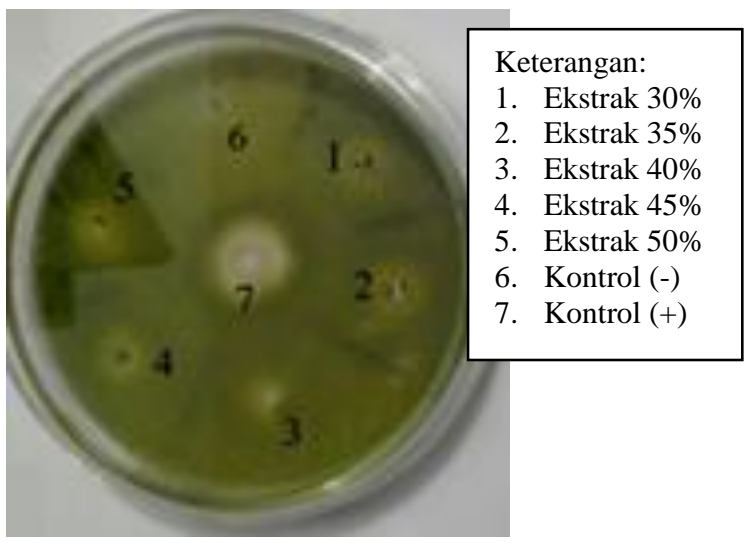

Gambar 2. Zona Hambat Ekstrak Daun Pegagan (Centella asiatica (L.) Urban) terhadap Jamur A. Flavus pada Konsentrasi 30\%, 35\%, 40\%, $45 \%$, dan $50 \%$

Berdasarkan hasil tersebut dapat disimpulkan bahwa pada konsentrasi 5\% sudah menunjukkan adanya luas zona hambat tapi masih lebar sehingga perlu dilakukan pengujian lebih lanjut untuk mengetahui Konsentrasi Hambatan Minimum (KHM) yaitu dengan memperkecil serial konsentrasi. Serial konsentrasi yang akan digunakan untuk pengujian lebih lanjut adalah 1\%, 2\%, 3\%, $4 \%, 5 \%, 6 \%, 7 \%, 8 \%, 9 \%, 10 \%$ yang dapat dilihat pada Tabel 2 .
Tabel 2. Hasil Uji Akhir Konsentrasi Hambatan Minimum (KHM) $\left(\mathrm{cm}^{2}\right)$ Ekstrak Daun Pegagan (Centella asiatica (L.) Urban) terhadap jamur A. flavus

\begin{tabular}{cllll}
\hline \multirow{2}{*}{ Konsentrasi } & \multicolumn{3}{l}{ Luas Zona Hambat $\left(\mathbf{c m}^{2}\right)$} & Rata \\
\cline { 2 - 4 } & 1 & 2 & 3 & -rata \\
\hline $1 \%$ & 0,3 & 0,31 & 0,29 & 0,30 \\
$2 \%$ & 0,32 & 0,31 & 0,31 & 0,31 \\
$3 \%$ & 0,35 & 0,35 & 0,33 & 0,34 \\
$4 \%$ & 0,38 & 0,38 & 0,4 & 0,39 \\
$5 \%$ & 0,39 & 0,39 & 0,4 & 0,39 \\
$6 \%$ & 0,4 & 0,4 & 0,43 & 0,41 \\
$7 \%$ & 0,5 & 0,51 & 0,51 & 0,51 \\
$8 \%$ & 0,51 & 0,52 & 0,52 & 0,52 \\
$9 \%$ & 0,52 & 0,52 & 0,54 & 0,53 \\
$10 \%$ & 0,53 & 0,53 & 0,55 & 0,54 \\
$\mathrm{~K}^{+}$ & 0,49 & 0,41 & 0,48 & 0,46 \\
$\mathrm{~K}^{-}$ & 0,00 & 0,00 & 0,00 & 0,00 \\
\hline
\end{tabular}

Berdasarkan Konsentrasi Hambat Minimum (KHM) ekstrak daun pegagan terhadap pertumbuhan jamur A. Flavus belum dapat diketahui karena pada konsentrasi $1 \%$ masih terdapat zona hambat yang luas. Maka perlu dilakukan penurunan serial konsentrasi sebesar $0,4 \%$, $0,6 \%, 0,8 \%$ dan $1 \%$ yang akan dilakukan uji lanjut.

Zona hambat ekstrak daun pegagan (Centella asiatica (L.) Urban) terhadap pertumbuhan jamur A. Flavus pada konsentrasi $1 \%$ - $10 \%$ dapat dilihat pada Gambar 3 dan Gambar 4.

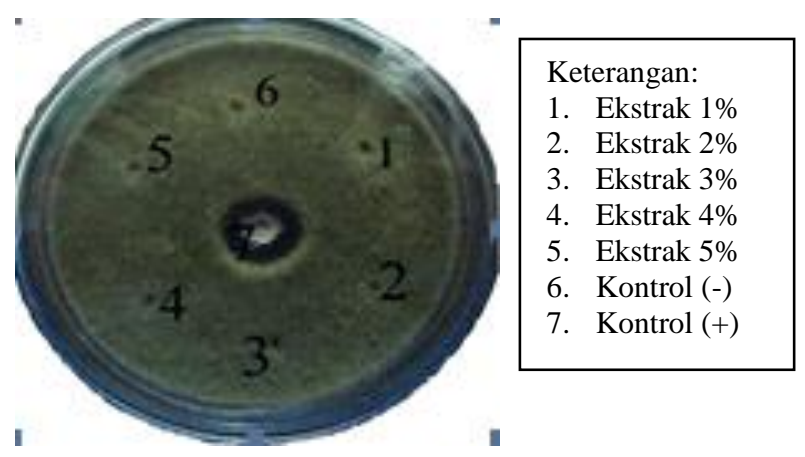

Gambar 3. Pengujian KHM Ekstrak Daun Pegagan (Centella asiatica (L.) Urban) terhadap Pertumbuhan jamur A. Flavus $1 \%, 2 \%, 3 \%, 4 \%$, dan $5 \%$. 
Efektivitas Ekstrak Daun Pegagan (Centella asiatica (L.) Urban ) terhadap Pertumbuhan Jamur Aspergillus flavus

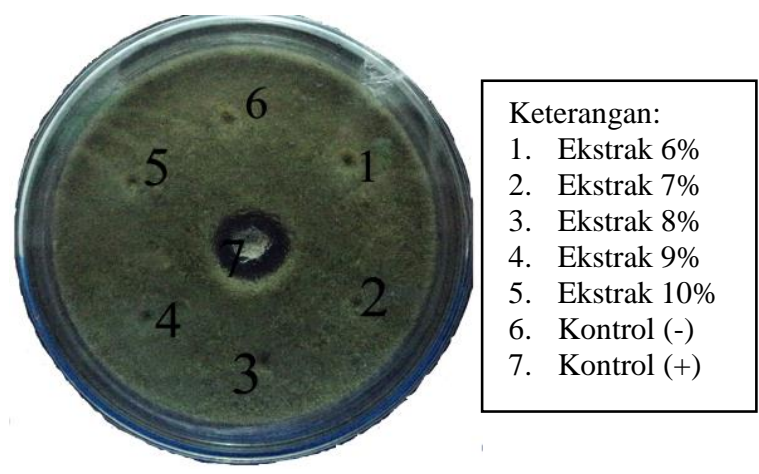

Gambar 4. Pengujian KHM Ekstrak Daun Pegagan (Centella asiatica (L.) Urban) terhadap Pertumbuhan jamur A. Flavus 6\%, 7\%, 8\%, 9\%, dan $10 \%$.

Berdasarkan uji lanjutan yang dilakukan dengan menggunakan serial konsentrasi sebesar $0,4 \%, 0,6 \%, 0,8 \%$ dan $1 \%$ maka dapat diketahui nilai dari Konsentrasi Hambat Minimum (KHM) pada serial konsentrasi $0,8 \%$ dengan ratarata luas zona hambat sebesar $0,10 \mathrm{~cm}^{2}$ karena pada serial konsentrasi 0,6 \% tidak ditemukan zona hambat, sehingga $0,8 \%$ dianggap sebagai KHM.

Zona hambat ektrak daun pegagan (Centella asiatica (L.) Urban) terhadap pertumbuhan jamur $A$. Flavus pada konsentrasi $0,4 \%$ - $1 \%$ dapat dilihat pada Tabel 3 dan Gambar 5.

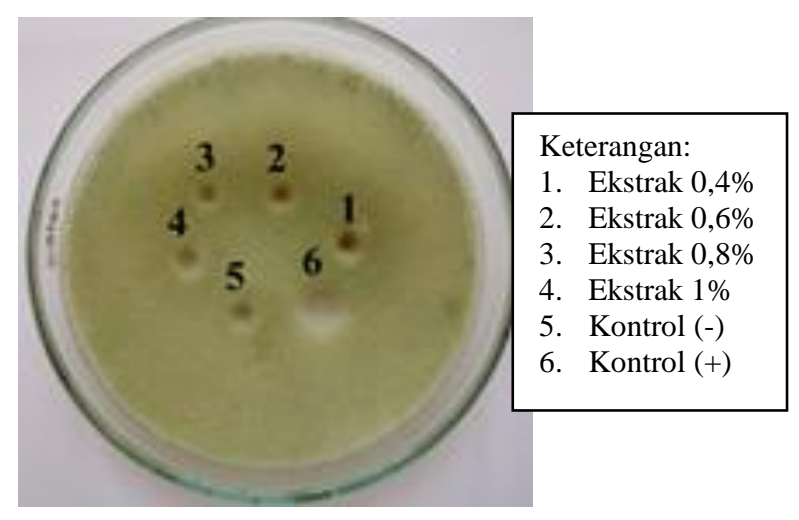

Gambar 5. Pengujian KHM Ekstrak Daun Pegagan (Centella asiatica (L.) Urban) terhadap Pertumbuhan jamur A. Flavus $0,4 \%, 0,6 \%, 0,8 \%$, dan $1 \%$
Tabel 3. Hasil Uji Akhir Konsentrasi Hambatan Minimum (KHM) $\left(\mathrm{cm}^{2}\right)$ Ekstrak Daun Pegagan (Centella asiatica (L.) Urban) terhadap Pertumbuhan jamur A. Flavus

\begin{tabular}{ccccc}
\hline \multirow{2}{*}{ Konsentrasi } & \multicolumn{3}{c}{$\begin{array}{c}\text { Luas Zona Hambat } \\
\left(\mathbf{c m}^{2}\right)\end{array}$} & $\begin{array}{c}\text { Rata- } \\
\text { rata }\end{array}$ \\
\cline { 2 - 4 } & 1 & 2 & 3 & \\
\hline $0,4 \%$ & 0,00 & 0,00 & 0,00 & 0,00 \\
$0,6 \%$ & 0,00 & 0,00 & 0,00 & 0,00 \\
$0,8 \%$ & 0,10 & 0,10 & 0,10 & 0,10 \\
$1 \%$ & 0,11 & 0,11 & 0,11 & 0,11 \\
$\mathrm{~K}^{+}$ & 0,49 & 0,41 & 0,48 & 0,46 \\
$\mathrm{~K}^{-}$ & 0,00 & 0,00 & 0,00 & 0,00 \\
\hline
\end{tabular}

Pertumbuhan A. Flavus didefinisikan sebagai bertambahnya jumlah spora pada medium biak agar. Hasil pengamatan pertumbuhan spora jamur pada beberapa serial konsentrasi dapat dilihat pada Tabel 4.

Sebelum menghitung jumlah spora pada beberapa serial konsentrasi, juga dilakukan penghitungan spora awal jamur atau stok awal jamur dan didapatkan jumlah spora sebesar 4,23 x $10^{9} \mathrm{sel} / \mathrm{ml}$. Berdasarkan Tabel 4. menunjukkan bahwa pada konsentrasi $0,4 \%$ memiliki jumlah spora sebesar 3,57 x $10^{9}$. Pada konsentrasi $0,6 \%$ memiliki jumlah spora sebesar $3,21 \mathrm{x}$ $10^{9} .0,8 \%$ merupakan Konsentrasi Hambat Minimum (KHM) yang didapatkan pada uji akhir memiliki jumlah spora 2,74 x $10^{9}$ sel/ml, sedangkan pada konsentrasi $1 \%$ memiliki jumlah spora sebesar 2,34 x $10^{9}$ $\mathrm{sel} / \mathrm{ml}$. Hal ini dikarenakan semakin besar konsentrasi maka kandungan zat aktif juga semakin besar sehingga semakin besar konsentrasi semakin besar pula kemampuan ekstrak untuk membunuh spora jamur. Sedangkan pada kontrol negatif memiliki jumlah spora sebesar 3,86 x $10^{9}$ dan pada kontrol positif memiliki jumlah spora $1,85 \times 10^{9}$. 
Efektivitas Ekstrak Daun Pegagan (Centella asiatica (L.) Urban ) terhadap Pertumbuhan Jamur Aspergillus flavus

Tabel 4. Hasil Penghitungan Jumlah Spora Pada Beberapa Serial konsentrasi Ekstrak Daun Pegagan (Centella asiatica (L.) Urban) terhadap Pertumbuhan jamur A.Flavus.

\begin{tabular}{cc}
\hline Konsentrasi & Jumlah spora \\
\hline Stok awal & $4,23 \times 10^{9}$ \\
$0,4 \%$ & $3,57 \times 10^{9}$ \\
$0,6 \%$ & $3,21 \times 10^{9}$ \\
$0,8 \%$ & $2,74 \times 10^{9}$ \\
$1 \%$ & $2,34 \times 10^{9}$ \\
$\mathrm{~K}^{-}$ & $3,86 \times 10^{9}$ \\
$\mathrm{~K}^{+}$ & $1,85 \times 10^{9}$ \\
\hline
\end{tabular}

Untuk memperjelas tentang penurunan jumlah spora setelah diberi perlakuan ekstrak daun pegagan dapat dilihat pada Gambar 6.

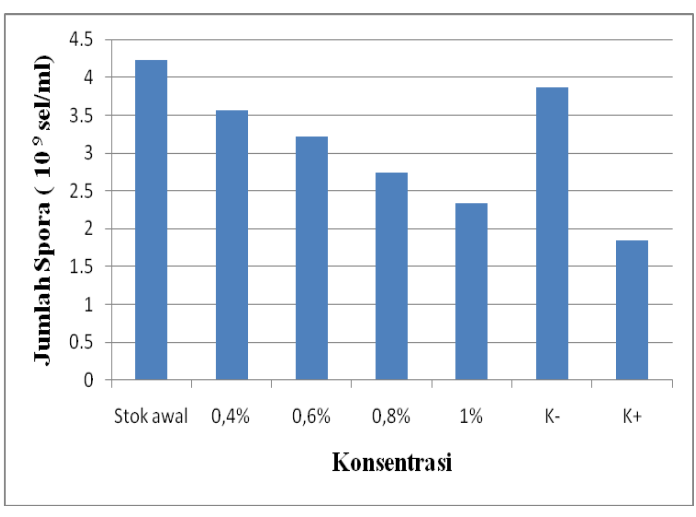

Gambar 6. Pertumbuhan Jumlah Spora Aspergillus flavus Setelah diberi Perlakuan Ekstrak Daun Pegagan (Centella asiatica (L.) Urban) pada Konsentrasi $0,4 \%, 0,6 \%, 0,8 \%, 1 \%$, kontrol positif dan negatif

Berdasarkan grafik diatas dapat diketahui dari konsentrasi $0,4 \%$ ke $1 \%$ mengalami penurunan jumlah spora. Hal ini dikarenakan konsentrasi yang semakin besar sangat mempengaruhi pertumbuhan jumlah spora. Pada kontrol positif jumlah spora semakin menurun dan pada kontrol negatif mengalami kenaikan.

Untuk mengetahui adanya pengaruh ekstrak daun pegagan (Centella asiatica (L.) Urban) terhadap pertumbuhan $A$.
Flavus dilakukan uji Analisis of Varian (ANOVA) dengan derajat kepercayaan 95 $\%(\mathrm{p}<0,05)$. Apabila terdapat perbedaan dilakukan uji Duncan dengan derajat kepercayaan $95 \% \quad(\mathrm{p}<0,05) \quad$ dengan menggunakan SPSS for Windows versi 24.

Hasil dari penelitian ini menunjukkan bahwa untuk mengetahui adanya perbedaan pengaruh dari beberapa serial konsentrasi ekstrak daun pegagan terhadap pertumbuhan A. Flavus pada konsentrasi 5\%, 10\%, 15\%, 20\%, 25\%, $30 \%, 40 \%, 45 \%, 50 \%$ maka dapat dilakukan uji statistik ANOVA dengan taraf kepercayaan 0,05 .

Tabel 5. Hasil Analisis ANOVA

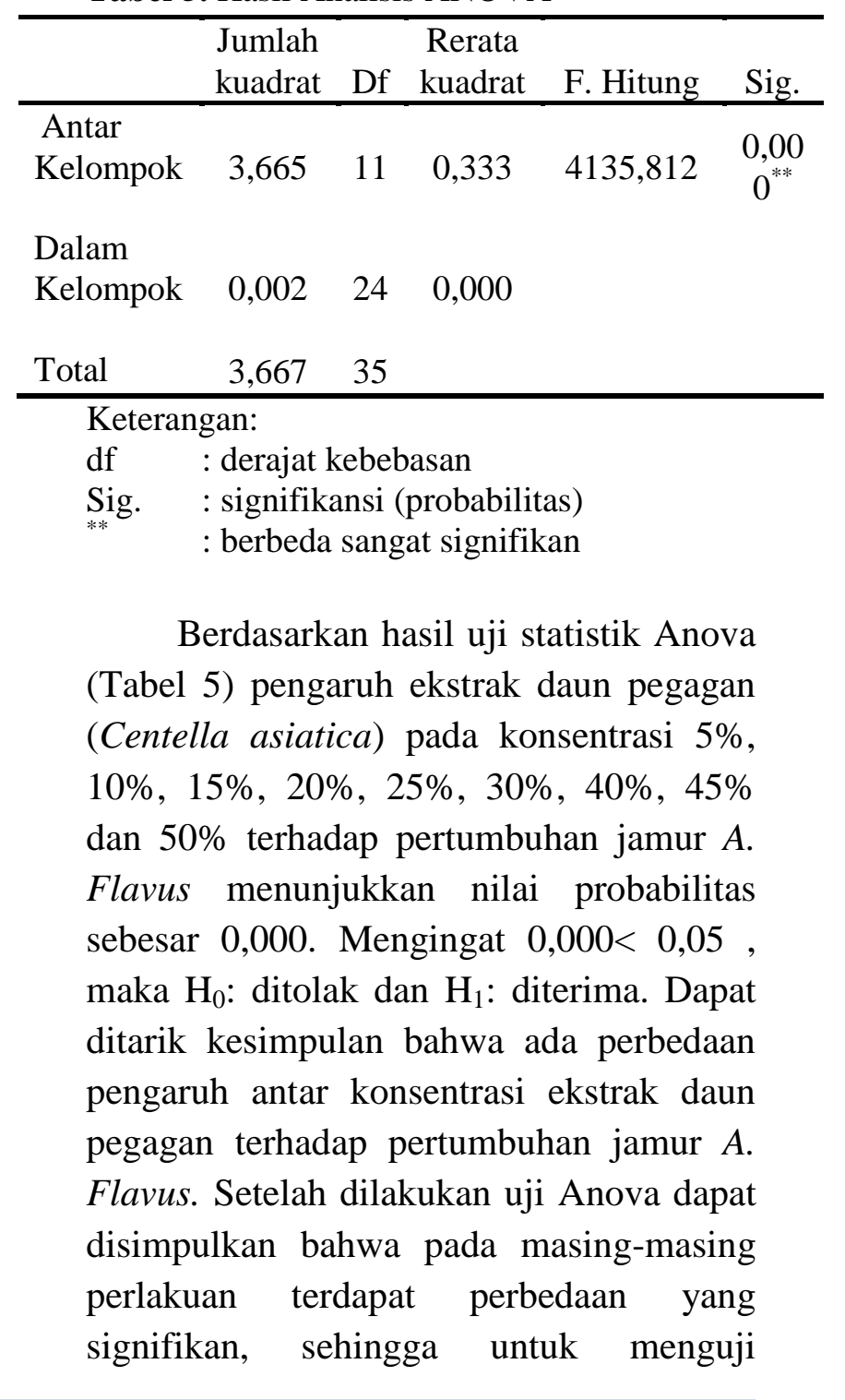


Efektivitas Ekstrak Daun Pegagan (Centella asiatica (L.) Urban ) terhadap Pertumbuhan Jamur Aspergillus flavus

perbedaan diantara semua pasangan perlakuan dilanjutkan dengan uji Duncan. Berdasarkan hasil uji statistik menggunakan Duncan diperoleh hasil berbeda nyata atau berbeda signifikan

Ekstrak daun pegagan akan berdifusi ke dalam medium PDA di sekeliling sumuran. Hasil penelitian menunjukkan bahwa ekstrak daun pegagan dapat menghambat pertumbuhan jamur $A$. Flavus, hal ini ditunjukkan dengan adanya zona bening atau zona hambatan di sekeliling sumuran. Zona hambat yang terbentuk memiliki ukuran yang berbedabeda pada masing-masing konsentrasi. Semakin kecil konsentrasi, maka semakin sedikit jumlah zat aktif yang terlarut di dalam ekstrak, sehingga semakin rendah kemampuan dalam menghambat pertumbuhan suatu jamur, dan sebaliknya.

Berdasarkan hasil penelitian yang dilakukan oleh Njoki et al. (2017) menunjukkan kandungan triterpenoid yang masuk dalam kelompok terpenoid sebesar $9,8 \%$ yang masuk dalam komponen bioaktif yang mampu menghambat pertumbuhan mikroba. Pada umumnya mekanisme senyawa antijamur atau mekanisme penghambatan pertumbuhan jamur dapat dibedakan menjadi beberapa macam yaitu pertama dengan gangguan pada membran sel. Gangguan ini dapat terjadi karena adanya ergosterol di dalam membran sel jamur. Ergosterol merupakan komponen sterol yang sangat penting, yang mudah diserang oleh antibiotik turunan polien dan obat jamur yang lain. Komplek polien ergosterol yang terjadi dapat menyebabkan kebocoran dari membran sel dan akhirnya lisis (Jawetz \& Adelberg, 1996:157). Kedua yaitu dengan penghambatan perkembangan jamur. Antimikroba adalah suatu senyawa yang mampu menghambat pertumbuhan maupun membunuh mikroorganisme. (Pelczar \& Chan (1988: 450) mengatakan bahwa makin tinggi konsentrasi suatu zat antimikroba akan semakin cepat sel mikroorganisme terbunuh atau terhambat pertumbuhanya.

\section{KESIMPULAN}

Berdasarkan penelitian yang telah dilakukan dapat disimpulkan sebagai berikut:

a. Ekstrak daun pegagan (Centella asiatica (L.) Urban) berpengaruh terhadap pertumbuhan jamur Aspergillus flavus.

b. Ekstrak daun pegagan (Centella asiatica (L.) Urban) mempunyai Konsentrasi Hambat Minimum (KHM) terhadap pertumbuhan jamur Aspergillus flavus pada konsentrasi $0,8 \%$.

c. Jumlah spora pada Konsentrasi Hambat Minimum (KHM) pada konsentrasi $0,8 \%$ sebesar $2,74 \times 10^{9} \mathrm{sel} / \mathrm{ml}$

\section{DAFTAR RUJUKAN}

Costa, F. D., Barber, C. J. S., Kim, Yeonbok, Reed, D. W., Zhang, H., FettNeto, A. G., \& Covello, P. S. (2017). Molecular cloning of an esterforming triterpenoid: UDP-glucose 28-O-glucosyltransferase involved in saponin biosynthesis from the medicinal plant Centella asiatica. Plant science, 262, 9-17. dilihat 10 April 2018 https://doi.org/10.1016/j.plantsci.201 7.05 .009

Herzallah, S. M. (2013). Aflatoxin B1 residues in eggs and flesh of laying hens fed aflatoxin B1 contaminated diet. American Journal of 
Agricultural and Biological Science, 8 (2), 156-161.

Hua, S. S. (2013). Biocontrol of Aspergillus flavus by Pichia anomala. FORMATEX, 1067-1072.

James, J. T., \& Dubery, I. A. (2009). Pentacyclic triterpenoids from the medicinal herb, Centella asiatica (L.) Urban. Molecules, 14, 3922-3941.

Jawetz, M., \& Adelberg. (1996). Mikrobiologi Kedokteran Edisi 20. Jakarta : Penerbit Buku Kedokteran EGC

Njoki, L. M., Okoth, S. A., \& Wachira, P. M. (2017). Effects of Medicinal Plant Extracts and Photosensitization on Aflatoxin Producing Aspergillus flavus (Raper and Fennell). International Journal of Microbiology. Volume 2017, Article ID 5273893, 9 pages

Okoth, S., Nyongesa, B., Ayugi, V., Kang'ethe, E., Korhonen, H., \& Joutsjoki, V. (2012). Toxigenic potential of Aspergillus species occurring on maize kernels from two Agroecological zones in Kenya. Toxins, 4(11), 991-1007.

Pelczar \& Chan. 1988. Dasar-dasar Mikrobiologi Jilid 2. Jakarta: UI Press

Singh, S., Gautam, A., Sharma, A., \& Batra, A. (2010). A Centella asiatica (L.): A plant with immense medicinal potential but threatened. International journal of pharmaceutical sciences review and Research, 4(2), 9-17. 